Euskal ikerketen aldizkaria | Revue d'études basques |

Revista de estudios vascos | Basque studies review

$10 \mid 2005$

Numéro $X$

\title{
Usage et dénonciation de la notion d'ethnie basque par l'anti-départementalisme en Pays basque nord
}

\section{Thomas Pierre}

\section{OpenEdition}

\section{Journals}

Édition électronique

URL : http://journals.openedition.org/lapurdum/60

DOI : $10.4000 /$ lapurdum.60

ISSN : 1965-0655

Éditeur

IKER

Édition imprimée

Date de publication : 31 décembre 2005

Pagination : 233-246

ISBN : 2-86781-409-X

ISSN : 1273-3830

Référence électronique

Thomas Pierre, « Usage et dénonciation de la notion d'ethnie basque par l'anti-départementalisme en Pays basque nord », Lapurdum [En ligne], 10 | 2005, mis en ligne le 01 avril 2008, consulté le 20 septembre 2020. URL : http://journals.openedition.org/lapurdum/60 ; DOI : https://doi.org/10.4000/ lapurdum.60 
Thomas PIERRE

Doctorant en Anthropologie - LAIOS - EHESS - Paris

\section{Usage et dénonciation de la notion d'ethnie basque par l'anti- départementalisme en Pays basque nord}

Depuis la manifestation départementaliste d'octobre 1999, j’analyse les débats suscités par la volonté d'institutionnalisation du Pays basque français. Le militantisme relativement puissant des associations départementalistes a généré, pour la première fois en Iparralde ${ }^{1}$, l'apparition d'associations dénonçant les aspirations politiques des différentes sphères basquisantes: le nationalisme, le départementalisme et le mouvement culturel basque.

\section{Les associations anti-départementalistes}

Dans un premier temps, en septembre 1999, à l'initiative de Jacques Betbeder, l'association Citoyen Adour Pyrénées Vivre Ensemble se constitue en réaction à la campagne départementaliste de l'Appel des Cent. Selon l'un de ses membres, que nous appellerons Peio, l'association comprend à la fois des "gens de droite et de gauche. C'est vrai que se retrouvent, là-dedans, plutôt des gens qui sont attachés à cet esprit républicain, à ses valeurs qui font qu'il y a une unité territoriale. Il y a une colonne vertébrale à laquelle il faut peut-être faire attention, avant de vouloir la casser $»^{2}$. Les statuts de cette association loi 1901 prévoient l'intervention dans le débat public de la "région », cette "région » correspondant au "Pays basque au sens large, avec le bas-Adour et le sud des Landes, et au Béarn, à notre département ${ }^{3}$. Il s'agit pour cette association de réaffirmer l'attachement, qu'elle pense «majoritaire », de la population au cadre «de notre pays, c'est à dire la République, la France avec ses valeurs et dans le respect de la démocratie, deux choses vraiment basiques $»^{4}$.

Selon le contenu du journal de CAP Vivre Ensemble, l'association veut dénoncer la tendance au développement de valeurs communautaristes et d'aspirations «ethnicistes" au sein de la société française dont le mouvement associatif départementaliste serait l'incarnation locale ${ }^{5}$.

Jusqu'en octobre 2003, l'association CAP Vivre Ensemble - à l'instar de deux formations politiques, le Parti Communiste et le Front National - est la seule structure associative à s'opposer catégoriquement et publiquement aux réformes institutionnelles soutenues par les départementalistes. Mais, à partir d'octobre 2003, alors que le mouvement Batera se met en place, naît, parallèlement, le Cercle Lissagaray ${ }^{6}$.

\footnotetext{
${ }^{1}$ Nous utiliserons indistinctement les expressions et termes suivants : Iparralde ( côté nord » en référence au Pays basque nord), Pays basque de France et Pays basque français.

2 Entretien le 27.01.2000 avec un membre de l'association Citoyen Adour Pyrénées Vivre Ensemble.

${ }^{3}$ Ibid.

${ }^{4}$ Ibid.

${ }^{5}$ Ibid.

${ }^{6}$ Le mouvement Batera est constitué des deux associations départementalistes, l'Association pour un Département Pays Basque (AND) et l'Association des Élus pour un Département Pays Basque (AED), ainsi que de la confédération des associations basques, Euskal Konfederazioa (EK), et
} 
Le Cercle Lissagaray se veut être un club de réflexion créé par Jean Espilondo, député et conseiller général socialiste d’Anglet-nord, Christian Aguerre, ancien rédacteur en chef de l'hebdomadaire La Semaine du Pays Basque, Jean-Claude Paul-Dejean, ancien professeur d'Histoire et Pierre Bidart, universitaire et responsable des Éditions Izpegi. Le nom retenu pour baptiser ce cercle est symbolique : Prosper-Olivier Lissagaray, né en 1839 à Auch de famille basque et décédé à Paris en 1901, est un journaliste du XIX ${ }^{\text {ème }}$ siècle qui s'engagea sous l'Empire et combattit pour la Commune sur les barricades. Socialiste, républicain, proche des idées de Blanqui, il n'appartint à aucun parti ${ }^{7}$. Le choix de ce personnage semble tout à fait correspondre à ce que l'anti-départementalisme veut prouver : on peut, au Pays basque, être Basque (le nom Lissagaray en atteste) et républicain (en référence à la France en tant qu'Etat-nation de tradition jacobine). Selon le porte-parole du Cercle Lissagaray, Christian Aguerre, cette association est issue d'une réflexion au sein du Parti socialiste local : à l'initiative de plusieurs socialistes dont Jean Espilondo, une première réunion destinée à "réfléchir » sur la situation de la région est organisée ${ }^{8}$. Cette structure doit permettre à la sensibilité de "gauche républicaine », de se réunir, d'échanger et d'essayer de structurer une réflexion, qui, à terme, doit être rendue publique.

Pour Christian Aguerre, le cercle ne souhaite ni se substituer à un parti, ni servir de laboratoire d'études à "un homme de gauche », sous-entendu Jean Espilondo. Dans ce club se retrouvent à la fois et de façon majoritaire des socialistes, mais aussi des gens non-encartés se réclamant «de gauche», et de nombreux enseignants. Les membres sont pour moitié des actifs et pour moitié des inactifs. Certains sont bascophones ${ }^{9}$.

La première intervention du club dans la presse a lieu la veille de la manifestation du 9 octobre 2003 organisée par la " plate-forme » départementaliste Batera. Le club se plaint alors du fait que personne n'ait pris position sur le cahier des charges présenté pas Batera, qui constitue, selon lui, une "caisse de résonance pour les nationalistes » ${ }^{\mathbf{1 0}}$. La «plate-forme » Batera n'aurait pour effet que de contribuer à la construction nationale basque, servant ainsi les objectifs des nationalistes ${ }^{11}$. Aussi, les revendications de Batera auraient pour vocation de " territorialiser pour mieux ethniciser ». Le club s’inquiète du fait que Batera, par la revendication départementaliste, veuille créer une "structure communautariste fondée sur la culture et la langue ${ }^{12}$. Christian Aguerre précise que le cercle est "foncièrement contre le communautarisme qui s'exprime au Pays basque et qui est une sorte d'institution en Grande-Bretagne. La France, elle, s'est fondée sur tout autre chose que l'adjonction de communautés ${ }^{13}$.

Selon Christian Aguerre, le club n'a pas de lien avec l'association CAP Vivre Ensemble si ce n'est que l'un des fondateurs du cercle, Jean-Claude Paul-Dejean, appartient à cette association. Il est cependant évident que le Cercle Lissagaray et l'association CAP Vivre Ensemble se rejoignent sur un certain nombre de points, et notamment sur leur représentation du nationalisme basque. De même, pour le

d'Euskal Laborantxarien Batasuna (ELB), le syndicat agricole abertzale.

${ }^{7}$ «Un exemple parfait de manipulation de l'opinion » selon le Cercle Lissagaray », La Semaine du Pays basque, du 9 au 15 octobre 2003, p 8.

${ }^{8}$ Entretien le 20.07.2004 avec Christian Aguerre, membre du Cercle Lissagaray.

${ }^{9}$ Ibid.

${ }^{10}$ Bayle-Siot Dominique, « L’opinion manipulée », Sud-Ouest, vendredi 10 octobre 2002, p.2-2.

${ }^{11}$ Ibid.

${ }^{12}$ Entretien le 20.07.2004 avec Christian Aguerre, membre du Cercle Lissagaray.

${ }^{13}$ Ibid. 
Cercle Lissagaray comme pour CAP Vivre Ensemble, la revendication départementaliste correspond à un objectif qui relève de l' "ethnicisme, au sens très large du terme », qui, à terme, vise à faciliter une unification des provinces "dites historiques du Pays basque, quatre d'un côté - en Espagne - et trois en France ». Aussi, " au nom de la République, au nom de la conception que nous avons de la laïcité », le Cercle Lissagaray - tout comme pourrait le formuler un membre de l'association CAP Vivre Ensemble - s'oppose à la création d'une structure institutionnelle qui "se calquerait sur une définition strictement culturelle et identitaire d'un territoire ». Selon Christian Aguerre, la République française s'est fondée sur "des notions de liberté, d'égalité et de fraternité qui vont au-delà de cette conception qui relève de l'Ancien Régime ${ }^{\mathbf{1 4}}$.

La création du Club Lissagaray constitue donc une nouveauté dans la nature de l'opposition au projet. Celle-ci ne vient plus seulement, selon les termes de Renaud d'Elissagaray, figure du départementalisme, d'un "groupuscule de droite », allusion à l'association CAP Vivre Ensemble, mais aussi désormais d'une gauche dite républicaine ${ }^{15}$.

Le discours de ces deux associations, hostile à toute évolution institutionnelle du Pays basque de France, a pour fond une même représentation du militantisme basque : sa supposée tendance à l'ethnicisme. L'opposition aux revendications institutionnelles basques fait de la question identitaire son terrain rhétorique privilégié avec l'idée, toujours sous jacente, de l'existence d'un communautarisme, dans le sens péjoratif du terme, voire d'un racisme basque.

L'opposition au projet départementaliste assimile les revendications basques au mieux à des réactions de crise doublées de nostalgies passéistes, au pire à des enfermements essentialistes teintés de nationalisme xénophobe. Ainsi, le Pays basque n'échappe pas au phénomène décrit par Jean-François Gossiaux qui note que «la tendance dans les pays d'Europe occidentale, au tournant du XXI ${ }^{\text {ème }}$ siècle, est de connoter négativement la nation et - surtout - le nationalisme. Mais en d'autres régions, où peuvent précisément se situer les centres d'intérêt du « spécialiste » occidental, les préjugés implicites ne vont pas forcément en ce sens. L'ambiguïté est quasi constitutive du sujet ${ }^{16}$. Jean-François Gossiaux précise que « si le mot nation sent le souffre dans l'univers scientifique, c'est qu'il est un mot clé de l'univers politique moderne - la modernité, en l'occurrence, commençant au $\mathrm{XIX}^{\text {ème }}$ siècle, avec la fin des « anciens régimes " " ${ }^{17}$.

Dans ce cadre idéologique, les aspirations départementalistes sont vécues comme la volonté de reconstitution des institutions d'Ancien Régime, à savoir la réhabilitation des trois provinces basques du nord incarnées politiquement par l'institution départementale. Aussi, l'association CAP Vivre Ensemble et le Cercle Lissagaray, se veulent être les vecteurs du rappel à la primauté de la raison universelle et des principes démocratiques sur les passions locales.

\section{La dénonciation d’un complot : la complicité départementaliste-nationaliste}

\footnotetext{
${ }^{14}$ Ibid.

${ }^{15}$ Iban Etxezaharreta, "Dans quel camp est l'imposture”, Le Journal du Pays Basque-Euskal Herriko Kazeta, samedi 11 et dimanche 12 octobre 2003.

${ }^{16}$ Gossiaux (2002 : p.46).

${ }^{17}$ Gossiaux (2002 : p.47).
} 
L'argumentaire de l'opposition au projet est fréquemment construit autour du soupçon de complicité implicite entre d'une part, les associations départementalistes ${ }^{18}$ et les membres locaux de partis nationaux traditionnels et, d'autre part, les mouvements nationalistes basques. Christian Aguerre estime que les débats politiques sont le monopole des nationalistes «toutes tendances confondues ». Il faut ici entendre par l'expression «toutes tendances confondues », l'ensemble des milieux plus ou moins basquisants, à savoir autant les nationalistes que les associations départementalistes ou les mouvements culturels basques. Aussi, la volonté de co-officialisation de la langue basque, qui est traditionnellement soutenue par le militantisme nationaliste basque, mais aussi par le départementalisme, prouve, selon l'opposition au projet, cette complicité, et illustre le fait que la revendication départementaliste n'est pas purement administrative $^{19}$. Ainsi, l'association CAP Vivre Ensemble s'indigne du fait que l'AED et l'AND, baptisées, pour l'occasion, d' " associations scissionnistes «modérées $» »^{20}$, admettent la présence, dans leurs rangs, d'élus abertzale ${ }^{21}$. De cette présence, elle conclut que les objectifs de la démarche départementaliste sont douteux. CAP Vivre Ensemble reproche alors à la revendication sa confusion entre «plan politique » et "argumentation économique » dans laquelle elle la suspecte de s'inscrire. Selon Peio, la revendication départementaliste n'est pas constituée «que de séparatistes ». Mais il en vient à se demander pourquoi «des gens » qu'il qualifie de "modérés» ne voient pas «le danger». Il entend par le terme "danger » le fait que la revendication départementaliste soit également " portée à bout de bras par le $P N V^{22}$, par la branche Euskal Herritarrok ${ }^{23}$, par des gens qui, plus ou moins ouvertement, disent qu'ils oeuvrent pour l'indépendance de la nation basque ». Il dit respecter toute opinion, mais pense qu'il ne faut "pas se voiler la face », qu'il ne faut pas «être naïf $»^{24}$.

Parallèlement à cet argument dénonçant l'«hypocrisie» du mouvement départementaliste, il y a également chez les opposants au projet une crainte des positions nationalistes basques espagnoles quant à la départementalisation du Pays basque français. L'opposition met en avant le risque de surenchère qui pourrait déboucher sur un climat politique semblable à celui du Pays basque espagnol.

Au soupçon de l'alliance avec le nationalisme s'ajoutent les thèmes du complot, et de l'annexion : "ces beaux messieurs ne peuvent pas nier qu'ils sont les alliés objectifs des séparatistes et des annexionnistes. Les uns commencent par

${ }^{18}$ L'Association pour un Nouveau Département (AND) et l'Association des Elus pour un Département Pays Basque (AED).

19 Entretien le 27.01.2000 avec un membre de l'association Citoyen Adour Pyrénées Vivre Ensemble.

${ }^{20}$ Association Citoyen Adour Pyrénées Vivre Ensemble, Journal de l'association Citoyen Adour Pyrénées Vivre Ensemble, n 1, octobre 1999.

${ }^{21}$ Le terme abertzale signifie " patriote » en langue basque. Il sert à la désignation et à l'auto désignation des nationalistes basques.

${ }^{22}$ PNV : Parti nationaliste basque ; en langue basque EAJ : Eusko Abertzale Jeltzalea. Parti conservateur dit «modéré » au pouvoir dans la Communauté Autonome d'Euskadi depuis 1978, année de création du statut des autonomies régionales espagnoles.

${ }^{23}$ EH : Euskal Herritarrok (Nous, Citoyens basques), parti politique s'étant substitué à Herri Batasuna. Herri Batasuna (Unité Populaire) coalition indépendantiste basque d'extrême gauche considérée comme la vitrine politique d'ETA.

${ }^{24}$ Entretien le 27.01.2000 avec un membre de l'association Citoyen Adour Pyrénées Vivre Ensemble. 
demander la partition du département, les autres, aidés par ce premier pas, continueront en exigeant la partition du territoire national $»^{25}$.

Ces inquiétudes, ces réticences, ou ces hostilités, liées à la peur de l'extension en Pays basque nord des caractéristiques de la situation politique du Pays basque sud reposent alors aussi sur la dénonciation des positions et aspirations politiques basques espagnoles.

\section{La notion d'ethnie basque : une boîte à idées pour l'anti-départementalisme}

Le discours anti-militantisme basque s'appuie sur le rejet de l'idée d'ethnie basque, mais aussi, paradoxalement - nous le verrons ultérieurement - sur la croyance en l'existence de cette ethnie. En effet, la création d'un département sous «appellation Pays basque » apparaît être un "découpage territorial » ayant, "qu'on le veuille ou non, une connotation ethnique sinon sous-jacente qui est évidente ». La volonté de "déterminer une zone basque, Pays basque " est dénoncée :

"Nous avons de l'autre côté, une revendication indépendantiste qui veut s'appliquer aux 159 communes des trois provinces basques telle que la mouvance nationaliste la revendique. Cela a été décrit, 159 communes. Ils les ont déjà déterminées. Regardez à Euskal Telebista ${ }^{26}$, la carte météo, elle est faite pour eux. Comment être naïf et penser qu'en allant au devant, en faisant nous-mêmes, en France, ce découpage-là, nous ne servirions pas, quelque part, les intérêts des gens qui veulent, eux, l'indépendance ${ }^{27}$.

Aussi, pour l'association CAP Vivre Ensemble, la revendication d'un département apparaît comme un danger. L'association va jusqu'à évoquer l'idée de balkanisation, au sens journalistique du terme. "Je ne veux surtout pas voir un jour ici la Bosnie ou l'Irlande », déclare Peio. Cette peur est particulièrement visible dans le journal de l'association CAP Vivre Ensemble. Un auteur anonyme y écrit que le projet de département est fondé sur un " communautarisme ethnique » inquiétant et que, "faire référence à la communauté des Basques, c'est faire appel à des notions ethniques ». D'autre part, ce même auteur estime que "dans un territoire donné, organiser la vie publique ou concevoir les structures administratives en prenant comme élément de référence les communautés, cela s'appelle le communautarisme. Or, les zélateurs de la partition des PyrénéesAtlantiques mettent en valeur l'histoire, les traditions, le particularisme des Basques, souvent en les opposant à ceux des Béarnais. Ils distinguent ainsi une communauté, celle qui parle basque, parmi l'ensemble de la population, qui dans sa totalité parle le français. Certains vont même jusqu'à envisager (...) une coofficialisation de la langue basque, à parité avec le français, dans le futur département. Iront-ils jusqu'à une uniformisation ethnique ? $»^{28}$.

\footnotetext{
${ }^{25}$ Association Citoyen Adour Pyrénées Vivre Ensemble, "Présents, M. le Préfet », Journal de l'association Citoyen Adour Pyrénées Vivre Ensemble, n 1, octobre 1999.

${ }^{26}$ Euskal Telebista : nom de la télévision basque qui depuis 1982 émet ses programmes des deux côtés des Pyrénées. Elle dispose de deux antennes, la première en langue basque et la seconde en langue espagnole. La couverture hertzienne du Pays basque français n'est quasi totale que depuis juillet 1998. Depuis octobre 1988, un correspondant est en poste à Bayonne.

${ }_{27}$ Entretien le 27.01.2000 avec un membre de l'association Citoyen Adour Pyrénées Vivre Ensemble.
} 
Ce témoignage, au-delà du fait qu'il illustre une fois de plus la crainte de certains d'une déstabilisation de leur paysage culturel et administratif, atteste du caractère largement passionné de la tonalité du discours anti-départementaliste.

Il s'avère donc qu'en Pays basque nord, et ce malgré le relatif phénomène d'intégration des idées abertzale sur la scène politique dans le cadre de l'initiative publique « Pays basque $2010 »^{29}$, le nationalisme basque reste, au sein de la grande majorité de la population, synonyme de risque et de peur.

Cette représentation du nationalisme basque en Iparralde est intimement liée à la perception des caractéristiques historiques du nationalisme basque et à l'actualité politique du sud. En effet, le débat autour de l'ethnie, en référence à une vision essentialiste du fait basque, prend une teneur particulière en Pays basque où la notion de race est parfois utilisée par certains nationalistes ou non-nationalistes basques. A ce sujet, Peio explique avoir lu en 1993, dans un quotidien espagnol, une interview de Xabier Arzalluz, alors président du Parti Nationaliste Basque ${ }^{30}$, qui déclarait que "s’il devait y avoir, sur une définition scientifique, une seule race en Europe, ce serait la race basque ».

Ainsi, pour réfuter les aspirations du mouvement départementaliste, le discours de l'opposition au projet dénonce, essentiellement par l'intermédiaire d'une critique de l'histoire du PNV, la tendance à déterminer le fait basque par des caractéristiques essentialistes.

Néanmoins, et paradoxalement, l'opposition au projet dont le discours est fidèle à l'idéologie académique, notamment scientifique, ayant servit à la formation de l’État français sous sa forme républicaine, s’appuie sur une pensée hiérarchisante qui fait des cultures dites régionales des espaces a-historisque. Ainsi, l’idéologie anti-départementaliste est fondée sur une représentation essentialiste du fait basque. En cela, on peut affirmer que tant le discours anti-départementaliste que le discours nationaliste traditionnel du PNV s'inscrivent finalement dans l'adhésion idéologique commune à la grille de lecture du monde établissant un lien inconditionnel entre caractères pensés « naturels » et faits de culture.

L’anti-départementalisme développe donc une vision stéréotypée de ce qu'est ou doit être une culture dite régionale, ceci à partir de la fidélité à la formulation idéologique d'une norme étatique : le centralisme d'Etat et sa variante française passée et actuelle, le jacobinisme.

\section{L’hybridité comme argument : brassage et non-basquité}

\footnotetext{
${ }^{28}$ Association Citoyen Adour Pyrénées Vivre Ensemble, Journal de l'association Citoyen Adour Pyrénées Vivre Ensemble, n 1 , octobre 1999.

${ }^{29}$ À partir de juillet 1992, une invitation officielle du sous-préfet de Bayonne est adressée aux élus politiques, aux représentants des milieux de l'enseignement, de la culture, du secteur économique et social, ainsi que des différents services publics, pour entreprendre une réflexion prospective et participative sur l'avenir du territoire du Pays basque français à l'horizon 2010. Une vaste entreprise de prospective territoriale et de sollicitation de la société civile est alors lancée. Deux conseils sont créés : le Conseil des Élus du Pays Basque et le Conseil de développement du Pays Basque.

${ }^{30} \mathrm{PNV}$ : Parti nationaliste basque ; en langue basque EAJ : Eusko Abertzale Jeltzalea. Parti conservateur dit «modéré » au pouvoir dans la Communauté Autonome d’Euskadi depuis 1978, année de création du statut des autonomies régionales espagnoles.
} 
Pour le membre de CAP Vivre Ensemble avec qui nous nous sommes entretenu, il n’y a pas, dans l'espace pensé comme devant correspondre au futur Département Pays Basque, «d'homogénéité culturelle, de population basque. Prenez la population du $B A B^{31}$, elle est très brassée en fait $»^{32}$. Tentant d'appuyer leur argumentaire sur la dénonciation du caractère "ethnique » du discours départementaliste, les opposants au projet participent paradoxalement à ce qu'ils dénoncent en soutenant, par exemple, que "dans les zones urbaines, ici comme ailleurs, il s'est réalisé un tel brassage de population qu'il faut être de mauvaise foi pour qualifier de basques tous les 120000 habitants de l'agglomération bayonnaise. C'est bien fallacieux de nommer "Pays Basque » la partie ouest du département des Pyrénées-Atlantiques » ${ }^{33}$.

Christian Aguerre déclare, lui aussi, pour montrer la pertinence de sa position qu' "il y a de moins en moins de Basques d'origine, les gens sont très mêlés. Les gens se sentent d'abord français avant d'être basques. Ils sont d'abord français, ceci rend impossible la constitution d'une nation basque. Le Pays basque, ça ne veut plus rien dire, il y a une majorité de non-basques ici $»^{34}$.

Ces témoignages montrent que, pour une partie au moins de l'opposition au projet, le supposé métissage des populations constitue le signe du caractère non-basque des zones les plus peuplées, en l'occurrence la côte basque largement urbanisée et à vocation touristique. Loin de réfuter « l'ethnicisme », c'est à dire la valorisation politique de l'ethnicité, qu'elle ne cesse de rejeter et de combattre, cette position participe de l'ethnicisme qu'elle révoque en s'appuyant sur une représentation intemporelle donc ethniste de l'identité adhérant ainsi à la croyance, préalablement dénoncée, en la nature essentialiste de l'ethnie basque. Les termes sont clairs, le «brassage » dont il est question signifie la non-basquité. Aussi, il s'avère que le recours aux idées polygénistes, à partir desquelles se formule l'argumentaire de l'opposition à la départementalisation, ne fait que réitérer de façon symétrique et inverse, le modèle raciste qu'il entend dénoncer. Au delà du fait que cette position soit paradoxale, elle participe à la stigmatisation du mouvement départementaliste. Aussi, une telle prise de position n'est légitime que dans le cadre de la légitimité totale de la représentation nationale de l'identité instaurant une hiérarchisation entre les cultures dites régionales et la culture nationale citoyenne.

L'effet central de cette idéologie est que s'instaure une hiérarchisation des cultures. Deux catégories apparaissent alors :

- La culture française est perçue comme apte à créer du politique. C’est une culture démocratique. Le fait qu'elle soit démocratique la rend, dans un contexte de forte croyance en la race - ou autrement dit, en référence au présupposé mythique d'une équivalence inconditionnelle entre traits de "nature » et faits de culture - apte au «métissage ». Tout le monde peut être français. En contre partie, cette faculté est parfois vécue comme ayant pour conséquence de rendre ce qui est pensé comme relevant de la culture française comme faible, comme peu culturel mais de "Culture » politique très forte ${ }^{35}$. L'idée de citoyenneté française, et en

31 « BAB » est l'abréviation de l'agglomération Bayonne-Anglet-Biarritz.

32 Entretien le 27.01.2000 avec un membre de l'association Citoyen Adour Pyrénées Vivre ensemble.

${ }^{33}$ Association Citoyen Adour Pyrénées Vivre Ensemble, «Résolument opposé au département Pays Basque », Journal de l'association Citoyen Adour Pyrénées Vivre Ensemble, n¹, octobre 1999.

${ }^{34}$ Entretien le 20.07.2004 avec Christian Aguerre, membre du Cercle Lissagaray.

${ }^{35}$ Nous entendons par le terme «Culture » l'idée de culture académique et en cela perméable et même vecteur et outil d'une formulation nationale donc politique de la culture. 
filigrane d’identité française, est perçue comme compatible avec la diversité culturelle.

- La culture basque est perçue, dans le cas où l'on admet qu'elle soit une culture, comme intrinsèquement non-apte à s'inscrire dans un cadre politique, comme par nature incompatible avec le champ politique de la citoyenneté. Le fait qu'elle soit pensée comme régionale, folklorique, bio-raciale et intemporelle suggère qu'elle est une culture forte donc pure, non apte au métissage. L’idée étant qu'en Pays basque, tout le monde ne peut pas être basque. Cela débouche sur l'idée qu'il serait tout à fait dangereux de la rendre politique.

Dans un numéro hors-série de la revue Atlantica Magazine, financée par le Conseil général des Pyrénées-Atlantiques, François Bayrou, s’inscrivant dans ce même type de représentations, écrit :

"Ce que j'ai toujours admiré chez le Basque, c'est la force de sa foi absolue dans le domaine religieux et politique. Il y a chez lui un aspect granitique. Pour lui, les choix sont tranchés : blanc ou noir. Le Basque est toujours prêt à aller au bout de son combat. Le Béarnais est, lui, souvent sceptique, comme s'il savait que toute médaille a son revers. L'ironie est chez lui une seconde nature, comme une sorte de politesse. Son intelligence est ennemie des certitudes. Il y a, chez les Béarnais, une manière de s'engager qui ne laisse jamais de doute sur leur sentiment. Je suis un peu comme cela. Mais, dans ma famille, heureusement nous savons mélanger les genres. Si je suis un pur produit du Béarn, ma femme est née à Bayonne d'une vieille famille boucalaise avec des racines à Bidaches, à Hasparren, à Saint-Péesur-Nivelle. Nos enfants sont vraiment basco-béarnais! C'est peut-être pourquoi j'aime tant les Pyrénées-Atlantiques » ${ }^{36}$.

L'argumentaire de ce texte suggère que l'identité basque ou béarnaise, et en filigrane l'identité dite régionale en général, correspond à des traits de caractères prédéfinis, à une condition culturelle intemporelle «ethnique » puisque strictement pensée comme un élément du passé. Cette position permet de montrer que la basquité ne peut être par nature que singulière et donc étrangère à la sphère du politique. En ce sens, elle est forcément pensée, dans le cas où elle se voudrait politique, comme "ethniciste" et en compétition avec l'identité citoyenne française considérée, elle, a contrario, du fait de sa condition nationale comme apte à l'évolution, à la pluralité. Ce numéro hors-série de la revue Atlantica Magazine est publié quelques semaines après la manifestation du 9 octobre 1999, en faveur du Département Pays Basque. La composition de ce numéro hors série apparaît en effet comme une réponse à la revendication départementaliste. En conséquence, on ne peut comprendre le ton de ce texte militant que si l'on prend en compte le fait qu'il s'inscrit dans ce contexte et qu'il a recours à l'usage de la distinction hiérarchisante entre culture régionale et nationale de manière à démontrer le caractère irréaliste des revendications du mouvement départementaliste. Par ailleurs, la référence à l'origine tient un rôle particulièrement important au sein de cette dialectique. Effectivement, l'utilisation des termes ou expressions «pur produit du Béarn », " née », "vieille famille », «racines » permet de confirmer le caractère par nature essentialiste de l'identité culturelle locale.

\footnotetext{
${ }^{36}$ Atlantica Magazine, « François Bayrou : «Pour son propre pays, on doit avoir les plus grandes
} fiertés » », Atlantica Magazine, hors série n¹, Hiver 1999 - Printemps 2000. 
Enfin, François Bayrou, président du Conseil Général des Pyrénées-Atlantiques, en conclut que ses «enfants sont vraiment basco-béarnais » : il considère donc ici les caractéristiques de la filiation comme étant les garants d'une équivalence de traits culturels, et participe donc clairement d'une vision « ethniciste » du monde. Dans le même état d'esprit, et, dans ce cas aussi, dans la perspective de récuser le projet départementaliste, Michel Casteigts, alors directeur général de la Communauté d'agglomération bayonnaise explique :

" Je suis un basco-béarnais, un Pyrénéen atlantique. Une frontière entre le Béarn et le Pays Basque passerait en plein milieu de mon patrimoine génétique! Mon regard sur les Pyrénées-Atlantiques en est certainement influencé. (...) L'espace Pyrénées-Atlantiques est d'une grande unité géographique. Des vallées montagneuses alimentent le fleuve et sa plaine, etc. (...) Le débat sur la frontière en Pyrénées-Atlantiques n'a donc pas de pertinence. L'avenir ne se prépare que dans le dépassement des frontières $»^{37}$.

La référence à la nature, en tant qu'outil de justification de convictions politiques, est dans ce cas encore plus explicite du fait de l'emploi de l'expression «patrimoine génétique » et de la référence à la géographie. De même, dans l'éditorial non signé de ce même numéro d’Atlantica Magazine intitulé «Ici, les Pyrénées sont Atlantiques », l'auteur écrit :

"Au couchant, la montagne semble naître de la mer. Elle puise dans la longue et forte houle du Golfe de Gascogne le rythme et l'ampleur de ses premiers plissements. Ce sont les coteaux du Pays basque, du Labourd et de la BasseNavarre. Très vite, ensuite, les reliefs s'accentuent, les sommets se font plus hauts... Dans les vallées de la Soule, de Barétous, d'Aspe et d'Ossau, (...) Mais ce pays n'est pas qu'un paysage. Deux peuples issus d'une même souche l'habitent. Basques et Béarnais... ${ }^{38}$.

Une nouvelle fois, l'idée d'origine et le recours au thème de la géographie ethnicisée permettent de justifier la cohérence affichée naturelle du département actuel. L'auteur utilise le mot "souche», et la qualifie de commune, de "même»: Basques et Béarnais seraient issus d'une même souche, aussi le département des Pyrénées-Atlantiques serait empreint d'historicité donc de légitimité, ce qui justifierait la cohérence de son existence.

Enfin, dernier exemple, Jean-Pierre Chevènement, candidat à la présidence de la République, déclare, pour justifier son opposition à la départementalisation du Pays basque, lors d'une visite à Bayonne, le 16 janvier 2002 alors qu'il est interpellé par le mouvement Démocratie pour le Pays Basque :

"Je ne suis nullement hostile au développement de la langue basque dans la mesure où ceux qui l'étudient le désirent. Nous sommes dans un régime de liberté... Le français est le trait d'union entre Bretons, Basques, Savoyards ou Franc-Comtois. La République respecte les différences, en même temps, elle les relativise... J'ai un peu de sang basque dans les veines par ma grand-mère, les Espagnols sont montés jusqu'en Franche-Comté ! Je reconnais qu'il y a quelque

\footnotetext{
${ }^{37}$ Rubrique « Cris et Chuchotements », La Semaine du Pays Basque, du 21 au 27 janvier 2000.

${ }^{38}$ François Bayrou, «Ici les Pyrénées Atlantiques », Atlantica Magazine, hors série n¹, Hiver 1999

- Printemps 2000.
} 
chose dans le caractère basque qui ne m'est pas étranger. Je suis d'accord pour ne pas laisser mourir la langue basque qui est une richesse de la France " ${ }^{39}$. L'hebdomadaire local La Semaine du Pays basque relate également les faits. Monsieur Chevènement «a pris congé très courtoisement en disant » aux membres de Démocratie pour le Pays basque : "la part de basque qui est en moi vous salue. Et l'autre aussi $»{ }^{40}$.

Ainsi, au sein de l'opposition au projet, ce qui est pensé comme relevant de l'identité basque ne l'est généralement qu'en fonction de la famille, de la filiation, de l'ascendance, de l'hérédité, et au final qu'en rapport à la nature. Notre informateur membre de l'association CAP Vivre Ensemble estime que la volonté d'apprentissage des langues régionales doit correspondre "à un terrain culturel familial». Il se dit "personnellement, un peu bouche bée de voir des gens qui viennent d'Amiens ou de Tourcoing ou d'ailleurs mettre des enfants à l'ikastola ${ }^{41}$ quand ils arrivent ici ${ }^{42}$. Selon lui, ce comportement est contraire à l'esprit de la République. Il qualifie de «rien de plus normale » l'attitude des personnes qui ont leurs « racines au Pays basque » et qui veulent voir "leur langue pratiquer, durer et être transmise à leurs enfants », mais estime qu' "il ne faut pas non plus en arriver à des extrêmes ». Il précise que les langues régionales doivent être "la continuité d'abord d'une tradition et d'une transmission avec un terreau quelque part, je conçois mal, en effet, que cela ne corresponde pas à une tradition » ${ }^{43}$.

Du point de vue linguistique, la demande de co-officialisation de la langue basque revient donc, pour les opposants au projet départementaliste, à ethniciser la région. Aussi, l'anti-départementalisme n'adhère pas à l'argument soutenant que l'enseignement public du basque au Pays basque éviterait que ne se désignent dans les écoles ceux qui veulent apprendre le basque et ceux qui ne veulent pas l'apprendre. Ce type de réforme ne fait pas sens pour les associations antidépartementaliste puisqu'elles considèrent que ce qui relève de la culture basque ne peut être politique, ne peut être pour tous. Le mouvement départementaliste, lui, tente de conceptualiser l'idée d'une "identité territoriale » qui impliquerait qu'en Pays basque tout le monde apprendrait le français et le basque, tout le monde parlerait ou en tout cas maîtriserait les deux langues. Avec cette logique territoriale, les associations départementalistes tentent de s'inscrire dans une logique étrangère à tout essentialisme.

Ainsi, paradoxalement, ce sont les opposants à la co-officialisation qui s'inscrivent - tout en la dénonçant - dans une logique ethnique : en soutenant que seuls apprendront le basque ceux qui voudront l'apprendre; ils désignent alors la communauté des Basques, la communauté des bascophones au sein du Pays basque lui-même.

Cette manière de présenter les choses permet de passéifier et de folkloriser la condition de Basque, de l'inscrire définitivement comme une culture « régionale » et «minoritaire » ; et d'écarter définitivement la supposition que cette culture minoritaire est aussi, du fait de sa non représentation politique, minorisée. À

\footnotetext{
${ }^{39}$ « Chevènement à Bayonne : non à l'officialisation de l'euskara et au département Pays Basque », Enbata, n¹712, 24 janvier 2002.

${ }^{40}$ « Pourquoi êtes-vous contre un département Pays basque ? », La Semaine du Pays Basque, du 18 au 24 janvier 2002.

${ }^{41}$ École primaire privée au sein de laquelle l'enseignement se fait exclusivement en langue basque.

${ }^{42}$ Entretien le 27.01.2000 avec un membre de l'association Citoyen Adour Pyrénées Vivre ensemble.

${ }^{43}$ Ibid.
} 
terme, cela permet de remettre en cause la pertinence du projet départementaliste. Ceci étant, cette vision du fait régional conditionnant une représentation donnée de l'identité ne fait pas l'unanimité au sein de l'opposition au projet.

Raphaël Lassallette, alors maire socialiste de la commune d'Hendaye estime par exemple que, "ce qu'il faut surtout, c'est que le basque revienne dans les familles et qu'à partir du travail que l'on fait à l'école, et en dehors de l'école, on fasse en sorte que ceux qui ne sont pas nés dans cette culture là puissent s'y intégrer. À partir de ce travail là, on retrouve la pratique du basque dans la rue, dans les réunions et dans les familles » ${ }^{44}$. Il ajoute qu' "on entend souvent dire "je suis basque » : je le suis dans la mesure où je défends la langue que je possède ou que je tente de me l'approprier. Ne parlons pas de Pays basque s'il n'y a plus de langue basque, tout le reste est du factice $»^{45}$.

On aura vu que les associations anti-départementalistes se donnent le rôle de résistants contre ce qu'elles affirment être des phénomènes de repliements identitaires ou de dérives ethniques. Les postures adoptées par l'opposition à toute évolution institutionnelle du Pays basque de France s'appuient autant sur une dénonciation du caractère supposé réactionnaire du nationalisme basque que sur une représentation ethnicisante $\mathrm{du}$ fait basque pensé sur le mode de l’intemporalité. Il est apparu que l'opposition au projet avait pour postulat l'idée d'incompatibilité - pensée naturelle - entre culture basque et sphère du public. Le discours des associations anti-départementalistes s'inspire autant des cadres idéologiques nationaux que de l'évolution des représentations de l'identité à l'échelle locale, de manière à faire de la question identitaire son terrain privilégié, avec l'idée, toujours sous-jacente, de l'existence intrinsèque d'un communautarisme, voire d'un racisme basque.

Alors même que l’opposition au projet dénonce les représentations ethnicistes de la société, son discours s'articule à partir d'une vision essentialiste du fait basque : le Pays basque est, en partie, composé "des Basques » considérés comme un ethnie à part - la notion d'ethnie renvoyant ici à un sentiment d'imperméabilité totale et intemporelle du groupe basque. Cette vision ne prend absolument pas en compte le caractère subjectif de l'identité et la complexité des consciences basques, bascophones ou non, et, au-delà, contribue à perpétuer l'idée selon laquelle monde basque et modernité seraient par nature antagonistes l'un de l'autre. S'il existe en Pays basque nord des formes de racisme d'opinion « comme partout», serait-on tenté d'écrire - il ne trouve ni nécessairement ni exclusivement sa source dans l'histoire du nationalisme basque.

\section{Bibliographie :}

\footnotetext{
${ }^{44}$ Entretien le 31.01.2000 avec Raphaël Lassallette, maire socialiste de la commune d'Hendaye.

${ }^{45}$ Lucien Etxezaharreta, « Raphaël Lassallette, citoyen engagé », Le Journal du Pays Basque, 23-24 février 2002.
} 
Amselle Jean-Loup, Logiques métisses, anthropologie de l'identité en Afrique et ailleurs, Éditions Payot\&Rivages, Paris, 1999, 257 p.

Gossiaux Jean-François, Pouvoirs ethniques dans les Balkans, Presses Universitaires de France, Collection Ethnologie, Paris, 2002, 217 p.

Laborde Denis (dir.), La question basque, Éditions L’Harmattan, 1998, 572 p.

Taguieff Pierre-André, La force du préjugé, essai sur le racisme et ses doubles, Éditions La Découverte, Collection Tel Gallimard, Paris, 1987, 645 p.

\section{Résumé :}

Entre 1999 et 2004, dans le cadre des mobilisations revendiquant la création d'un Département Pays Basque naissent deux associations, CAP Vivre Ensemble et le Cercle Lissagaray. Ces associations dénoncent les aspirations politico-culturelles du militantisme basque. Elles développent leur discours à partir de la dénonciation de la notion d'ethnie basque qui serait, selon elles, à la source de toutes revendications basquisantes. Paradoxalement, alors même qu'elles rejettent l'usage et la validité de cette notion, la structure de leur argumentaire dépend de l'adhésion idéologique à celle-ci. 